\title{
Curing Properties of Water-based Self-drying / Fast-drying Foundry Coating
}

\author{
Chunyi ZHAN ${ }^{1, a^{*}}$, Shengshan FENG ${ }^{1, b}$, Shuzhong XIE², Chunjing LIU², \\ Jiahao LIANG $^{2}$ and Yunhua GAO ${ }^{2}$ \\ ${ }^{1}$ School of mechanical and Electrical Engineering, Guangdong Institute of Science and Technology, \\ Zhuhai, 519090, China
}

${ }^{2}$ Zhuhai Doumen Fulian Molding Materials Industry Co.Ltd, Zhuhai, 519180, China

aemail: richardzhan@hotmail.com, bemail: fss8172@126.com

\begin{abstract}
Keywords: Water-based; Self-drying; Coating; Curing
Abstract:The article focuses on the self-drying curing characteristics of energy-saving and environmental friendly water-based self-drying / fast-drying foundry coating. Through check experiment, the differences of strength, humidity resistance and influence on the strength of resin sand when respectively using new water-based foundry coating, common water-based and alcohol-based coating are compared and studied. The results show that the coating strength of new water-based coating is significantly higher than that of common water-based coating and is almost the same as alcohol-based coating. The coating has a minimal impact on the strength of resin sand, and its humidity resistance is obviously better than that of common water-based and alcohol-based coating, for the residual water content of the coating is only about $1.4 \%$ after self-drying.
\end{abstract}

\section{Introduction}

Water-based self-drying / fast-drying foundry coating has the advantages of being safe, convenient in transportation, low cost, and contamination-free. It also has good suspension property and brushability, and fast air drying speed etc. It overcomes the problems of alcohol-based coating such as inflammability, explosibility, poisonousness, and suspension stability. It doesn't leave serious brush marks when brushing or have the problems of common water-based coating such as needing to dry, being difficult to dry, and easy to absorb moisture, etc. [1-6]. From the point of view of energy saving and consumption reducing, improving working conditions as well as production safety along with surface quality of castings and so on, water-based self-drying / fast-drying coating is the developing direction of sand casting coating.

The new water-based self-drying / fast-drying foundry coating is developed by using the natural refractory material without calcination or electric melting as base material and self-made normal temperative cured modified polymer emulsion organic adhesive as main self-drying / low temperature fast drying adhesive at room temperature as well as applying the fast-drying silicate adhesive as main high temperature adhesive. It has good brushability and low permeability under the condition of high viscosity and solid content (volatile content). It can also be fast drying at low drying temperature in a short time, or be fast surface drying using torch, gas, oxygen acetylene gas or hot blast short time rapid surface drying. Besides, this coating can be fast natural drying under the condition of high ambient temperature, low humidity and good ventilation conditions without worsening the sand strength. The dried coating has good moisture resistant absorption ability, which provides good conditions for foundry enterprises to save energy and improve environmental conditions and the quality of casting.

\section{Test instruments and methods}

\section{Self-drying time (h)}

Self-drying time of coatings is measured by QGZ type paint film drying time tester under the condition of $25^{\circ} \mathrm{C}$ and $80 \% \mathrm{RH}$, which characterizes drying speed of the coatings. The coatings, 
which are $0.5 \mathrm{~mm}$ thick, are placed on the planar basement of resin sand.

Wear loss

The wear loss of coatings is the characterization value of wear resistance of coatings and it characterizes the cohesive strength of coatings indirectly.

The wear loss of coatings is tested using JM-IV type paint film abrasion tester. The sample is a resin sand plate with a diameter of $105 \mathrm{~mm}$ and thickness of $10 \mathrm{~mm}$. The coatings, with the thickness of $1.0 \sim 1.5 \mathrm{~mm}$, are thoroughly dried and tested on $750 \mathrm{~g}$ load and $60 \mathrm{r}$ friction with grinding wheel. The quality difference of the coated circular plate before and after the test is the wear loss of coatings.

We adopt the "relative-strength" characterization when using the wear loss of coatings to compare the difference and the change of the coating strength. Suppose the relative strength of reference sample is one and the wear loss of it is $A_{0}$, while the wear loss of others is $A_{x}$, then the relative strength of some sample is $\mathrm{R}_{\mathrm{x}}=\mathrm{A}_{0} / \mathrm{A}_{\mathrm{x}}$.

\section{Water content}

The coating's water is measured by double disc infrared dryer and precision balance. And the surface heating temperature of the bearing sample plate is $140 \sim 220^{\circ} \mathrm{C}$.

\section{Test results and analysis}

\section{Self-drying curing characteristics of coating}

Foundry coating should not only have certain strength at room temperature, but also good strength at high temperature. According to such demand, we develop a curable modified polymer emulsion at room temperature as the main self-drying / low temperature quick drying adhesive. At the same time, we used a fast-drying type inorganic binder as the main high temperature adhesive, with the addition of the corresponding latent type hardener.

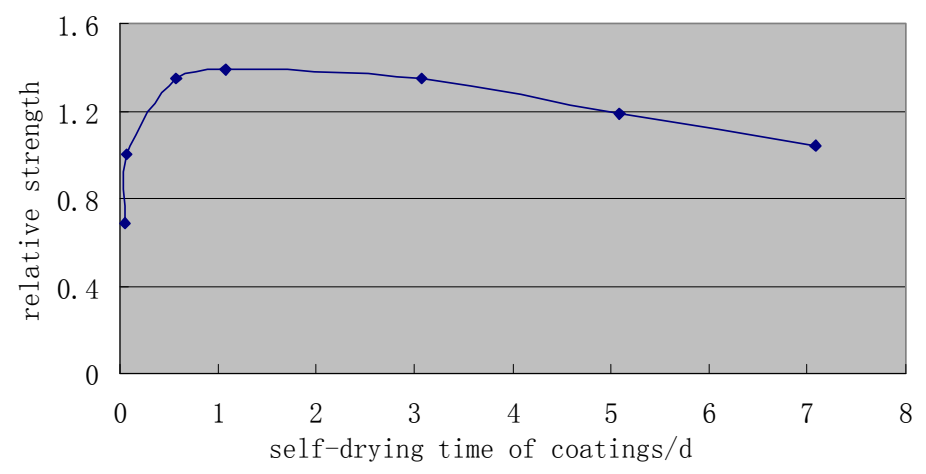

Fig.1. The self-drying curing characteristics of water-based self-drying coatings

Figure 1 shows how the strength of the new water-based self-drying coatings grows and changes over time, which demonstrates its self-drying curing characteristics. The process can be divided into the following four stages:

\section{(1)initial dehydration-transformation stage}

When water-based self-drying coating is applied under normal temperature, normal atmospheric pressure and open environment conditions of foundry production, as the contact surface area of the coating and the air increases significantly, the partial pressure difference of water and the curing agent on both sides of the interface makes the coating's water (including coating's diluent water and free water in binder) and latent curing agent (volatile lye) in the modified polymer emulsion binder evaporate. The air flow of a certain temperature can further promote the evaporation of water and the latent type curing agent, so that the coating begins to show signs of dehydration, and at the same time changes from alkaline to neutral and acidic without curing. At this stage, coating's strength has not been established yet. The time is about 10 30min.

(2) middle physical-chemical common curing stage

As its storage time increases, the coating continues to dehydrate. The polymer in the modified 
polymer emulsion is closed packed and physical hardening occurs. Under aluminum ion hydrolysis and capillarity of water insoluble organic fiber, free water in the fast-drying inorganic binder rapidly evaporates and loses, which causes inorganic binder to begin solidifing, and physical hardening also occurs. At the same time, the modified polymer emulsion decreases the critical concentration of gelation of inorganic binder thus induces the fast concentration of gelation, accelerating its physical hardening. Meanwhile, the coating has changed into acid, the zinc ions in the modified polymer emulsion gradually dissociate out of their complexes and interact with carboxyl anions on emulsion polymer linear molecular chain, thus water insoluble complexes is formed and polymer chain crosslinking is realized. Network structure polymer which does not dissolve in water is formed, leading to the chemical curing of coating. At this stage, physical hardening and chemical hardening occur simultaneously, and the strength increases rapidly. The time is about $30 \mathrm{~min} \sim 3 \mathrm{~h}$. The end point of this stage is the end point of self-drying time which is tested by paint film drying time tester. Now dehydration curing is completed (relative strength is set to 1). The initial and middle stage of the self - drying process is the self-drying time which is tested by paint film drying time tester.

\section{(3) later chemical curing stage}

As the coating's storage time continuously increases, physical curing of the coating is no longer happening, but the chemical curing of the modified polymer emulsion continues to exist and the strength peaks. This is the late self-drying process of the water-based self-drying coating. The time is about $3 \mathrm{~h} \sim 1 \mathrm{~d}$.

\section{(4)storage moisture absorption stage}

If the coating is kept in storage under normal temperature, normal atmospheric pressure, and open environment conditions of casting production, it will start to react with moisture absorption, which leads to the reduction of coating's strength. The time is $1 \mathrm{~d} \sim 7 \mathrm{~d}$. It reduces to the level of critical end point of self - drying time after seven days.

\section{Residual moisture after the coating's self-drying}

There are three forms of moisture in the coatings: one is free water, it is completely lost before heating to around $110^{\circ} \mathrm{C}$; the second is absorbed water, it is lost when heating to $140^{\circ} \mathrm{C} \sim 220^{\circ} \mathrm{C}$; the third is structural water, it is lost when heating to $400^{\circ} \mathrm{C} \sim 700^{\circ} \mathrm{C}$. In the drying process of water-based self-drying coating, most of the free water can be removed, but the absorbed water and structural water can not be removed.

If there is a lot of residual moisture after the drying of water-based self-drying coating, the gas of coating will become big, which makes it difficult to prevent the gas hole defect of casting. Therefore, we tested the changes of water content (including free water and most of the absorbed water) and the relative strength during the drying process of water-based self-drying coating, the preparation and self-drying conditions of the coating are both $28 \sim 29^{\circ} \mathrm{C}$ and $47 \sim 49 \% \mathrm{RH}$, as shown in figure 2.The measured self-drying time of the coating is 61 minutes.

It can be seen from figure 2 :

(1)The residual moisture no longer reduces after the coating's self-drying, and it always remains at $1.4 \%$, but the abrasion loss continues to decrease. It proves that the chemical curing reaction is still ongoing after the dehydration of physical curing of the water-based self-drying coating is finished.

(2)The experiment proves that the self-drying time, which is tested using QGZ type paint film drying time tester, accurately indicates the characteristic time point that the residual moisture no longer decreases (dehydration and curing are completed), it cannot indicate the characteristic time point that coating strength peaks. However, the self-drying time of the coating can be used as the characterization value of the curing speed of the coating, it reflects the relative level of the coating's curing speed.

(3) The residual moisture ( mainly composed of water) is only about $1.4 \%$ after the coating's self-drying. It has very little impact on the total gas of coating and provides a good condition for preventing the gas hole defect of casting. 


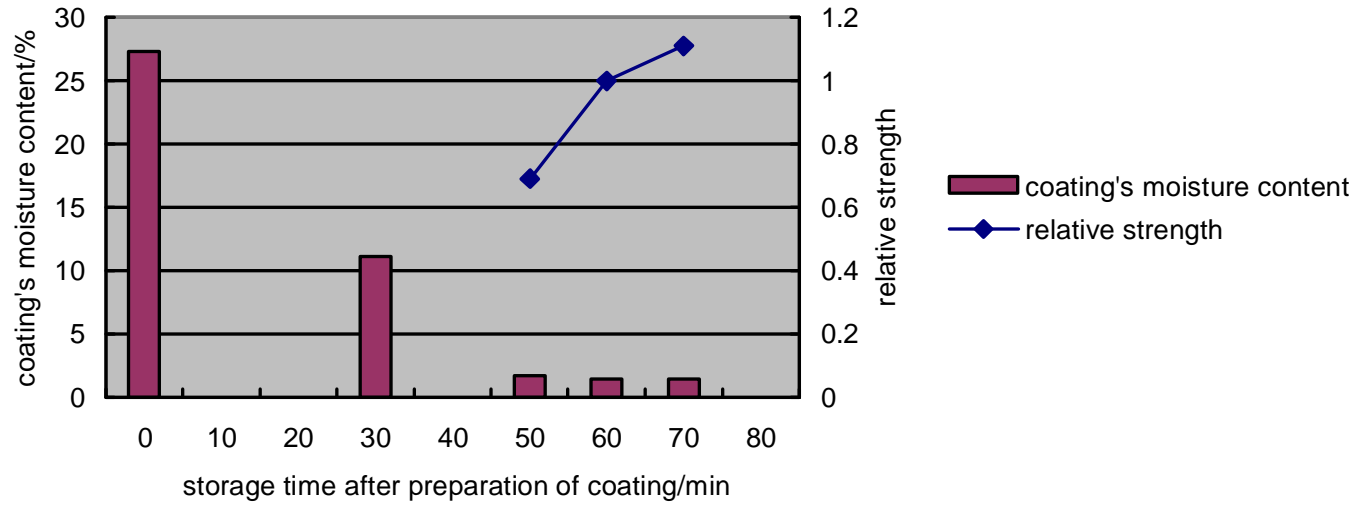

Fig.2. Variation of moisture content and relative strength of water-based self-drying coating in the drying process

\section{Humidity resistance of coating}

When the cured coating is stored, the coating may absorb moist if the humidity is high, and leads to the reduction of coating's strength and increase the amount of gas evolution from the coating.

In order to analyze the humidity resistance of this coating, we tested the variation of wear loss and relative strength of water-based self-drying coating common water-based coating and alcohol-based coating under the same storage conditions $\left(9 \sim 12^{\circ} \mathrm{C}, 38 \sim 51 \% \mathrm{RH}\right)$, as shown in figure 3 .
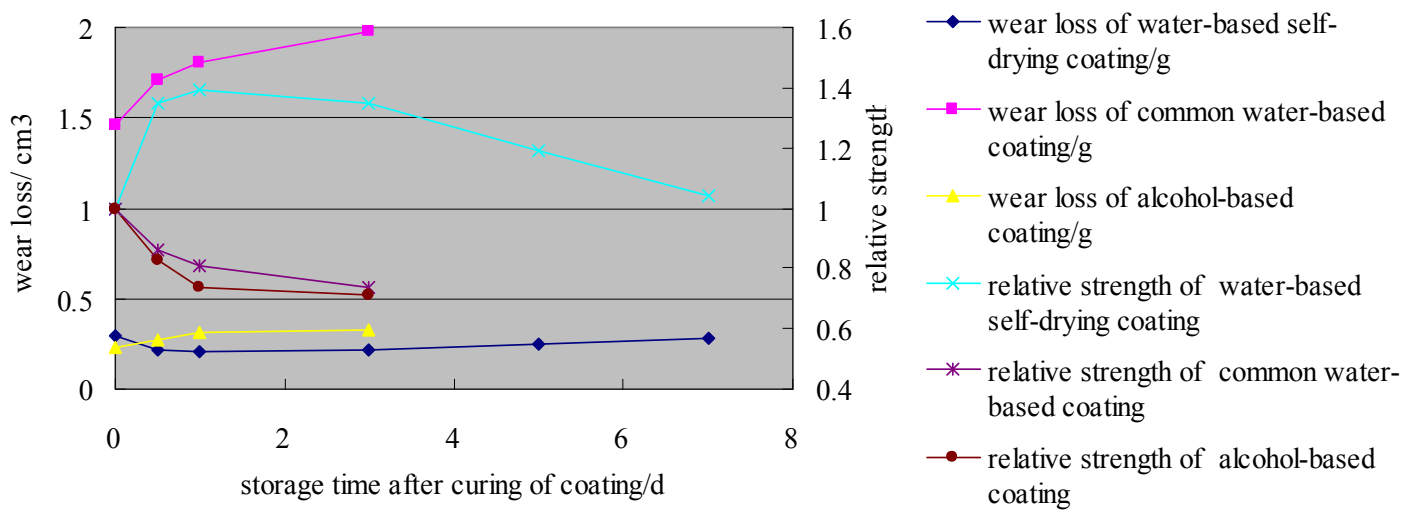

Fig.3. Variation of wear loss and relative strength of the three coatings on self-drying time of water-based self-drying coating after storage

It can be seen intuitively from figure 3 :

(1)After the storage of common water-based coating and alcohol-based coating, their strengths are always falling, both strengths have fallen by about 30 percent. In the early period, as the curing reaction continues, the strength of the water-based self-drying coating improves significantly to about 40 percent during the seven days of natural storage under room temperature. Subsequently due to the moisture absorption reaction of coating, its strength also decreases in the late stage, but it is always higher than the initial strength during the first seven days of observation period.

(2)The self-drying strength of water-based self-drying coating is equivalent to the combustion curing strength of the on-sale alcohol-based coating, but it is several times higher than dry strength of the on-sale common water-based coating.

Therefore, the humidity resistance of water-based self-drying coating is significantly better than that of common water-based coating and alcohol-based coating; the strength of water-based self-drying coating is significantly higher than that of common water-based coating and is equivalent to that of alcohol-based coating.

\section{The effect of coating on strength of resin sand}

In order to compare the effect of water-based self-drying coating, common water-based coating and alcohol-based coating on the strength of resin sand, we dipped coating single-side three kinds of 
coating (for 5s) in 8-shaped standard specimens (grain size is all 50/100 mesh) of acid self-hardening furan resin sand, after the coating was dried in a corresponding way (water-based self-drying coating was dried under the conditions of $23 \sim 30^{\circ} \mathrm{C}$ and $28 \sim 38 \% \mathrm{RH}$, began timing and testing after three hours; common water-based coating began timing and testing after drying at $120^{\circ} \mathrm{C}$ for one hour and then cooled to room temperature; alcohol-based began timing and testing after immediate kindling and drying and then cooled to room temperature,) the tensile strength of 8-shaped standard specimens of resin sand after different time intervals under the same conditions $\left(9 \sim 12^{\circ} \mathrm{C} 、 38 \sim 51 \% \mathrm{RH}\right)$ were compared and tested, as shown in figure 4.

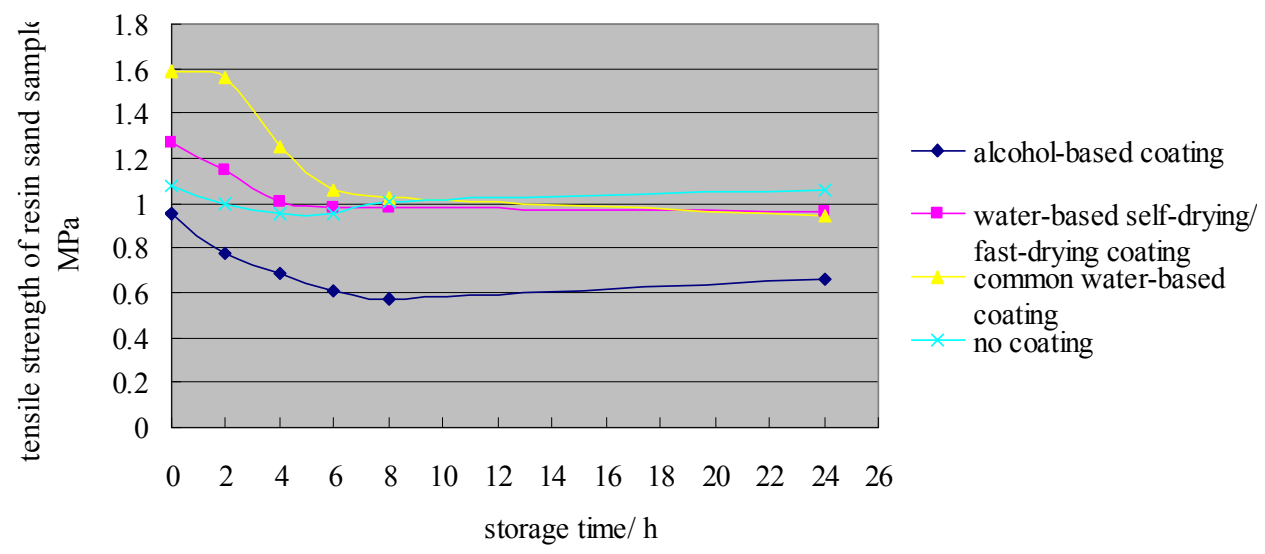

Fig.4. The effect of three coatings on tensile strength of resin sand

From the analysis of the table and figure it can be known:

(1)Alcohol-based coating influences the strength of resin sand most and significantly reduces the strength of resin sand. After storing for 24 hours, strength loss rate of coated alcohol-based coating reaches $38 \%$ compared with the non-coated resin sand sample, the loss rate of curing initial strength of the alcohol-based coating also reaches 31\% compared with the coated alcohol-based resin sand sample. The reason is that the solvent of the alcohol-based coating are methanol, ethanol and isopropanol, and they are all organic solvents; the residual organic solvent in resin sand is easy to make partial not fully cured resin film dissolved, meanwhile, the humidity resistance of the alcohol-based coating is poor, which leads to the significant decrease of the strength of resin sand.

(2)Because the common water-based coating is heated drying and curing, when the coating is heated and dried, it also makes the resin film of the resin sand which has not yet fully cured get further polymerization and strengthening, the strength of resin sand is significantly improved. But the binder of common water-based coating is general water-soluble inorganic binder. It is easy to absorb moisture and lose strength during storage after curing, the hygroscopicity of coating is strong, it is difficult to prevent the moisture from penetrating the internal of resin sand, and leads to dramatic decline of strength of both coating and resin sand; after storing for 24 hours, strength loss rate of heating and curing initial strength reaches $41 \%$ compared with the coated common water-based resin sand sample.

(3) Because the viscosity of water-based self-drying coating is high, the permeability of resin sand is low after dip coating, which makes the dissolution of water to resin film weak; after dip coating about three hours, the coating has been basically cured and gets higher strength, which makes the whole strength of resin sand sample add about $18 \%$ compared with the non-coated resin sample; after storing for 24 hours, because the humidity resistance of water-based self-drying coating is good (the reason is that the modified styrene-acrylic emulsion bond film in water-based self-drying coating has strong humidity resistance), loss rate of the initial strength of the 3 hours self-curing is $24 \%$ compared with the coated water-based self-drying resin sand sample, strength loss rate is only $9 \%$ compared with the non-coated resin sand sample.

Therefore, the influence of water-based self-drying coating on the strength of resin sand is the smallest in the three coatings. 


\section{Conclusion}

The curing mechanism of new water-based self-drying / fast-drying coating is the interaction of the following two kinds of reactions: one is the physical hardening caused by water evaporation loss, and the other is the chemical hardening after the acidic change of system. The self-drying curing process can be divided into the following three stages: initial dehydration-transformation stage、 middle physical-chemical common curing stage and later chemical curing stage. Under the conditions of $25^{\circ} \mathrm{C}$ and $80 \% \mathrm{RH}$, the coating can basically achieve natural drying within $1 \sim 3 \mathrm{H}$; its self-drying speed reaches international standards of similar products.

The residual water content of new water-based self-drying / fast-drying coating is only about $1.4 \%$, which provides good conditions for avoiding the blowhole defects of castings.

The strength of new water-based self-drying / fast-drying coating is significantly higher than that of common water-based coating and is almost the same as the alcohol-based coating. The effect on the strength of resin sand is the smallest among the three coatings.

The humidity resistance of new water-based self-drying / fast-drying coating is obviously better than that of common water-based and alcohol-based coatings.

\section{Acknowledgement}

In this paper, the research was sponsored by the Science and Technology Research and High-tech Industrialization Projects of Zhuhai City, Guangdong Province,China (Project No. 2011B020102013).

\section{References}

[1] Feng Sheng-shan, Xie Shu-zhong, Liu Chun-jing, et al. Technological properties of water-based self-drying / fast-drying foundry coating. China Foundry week Symposium(2014) 216-219

[2] Liu Sheng-yin, Sun Xing-hua, Jin Xiao-chun, et al. Development the Water-based coating for cold box process. China Foundry week Symposium(2008) 351-357

[3] Liu Cheng-yao. Property and Application on PVA Water-Based Air-Dried Coating. Foundry, 3 (1990) 23-27.

[4] Wei Zhao-lian, Cao Li-hong. Study on Phosphate No-bake Moldcoating. Journal of Wuhan Institute of Technology, 4 (1992) 40-46.

[5] Wei Zhao-lian, Cao Li-hong. The High Temperature Properties of Phosphate No-bake Moldcoatings. Special Casting \& Nonferrous Alloys, 5 (1994) 17-20.

[6] Hu You-fu. Production Test of JZ-1 Water-based Fast-drying Coatings. Auto Mobile Science \& Technology, 3 (1993) 23-28. 